\title{
IMPROVING FAMILY THERAPY TRAINING AND PRACTICE THROUGH STUDENT REFLECTIONS
}

\section{R Partab}

"The real integration between theory and practice will come not from a ponderous, rigid body of knowledge, but from the humility to learn from practitioners' experiences" (Jones \& Jordan, 1996:267).

\section{INTRODUCTION}

This paper documents student appraisals of a Family Therapy Practice Module and allows for students' reflective accounts to speak for themselves. The analysis aids in informing competent practice and programme content of the module, which constantly changes in shape and form. This module, like many others in institutions of higher learning, will be subjected to a quality assurance review exercise by not only our discipline of social work but also through an institutional audit. Our institution's quality assurance committee will review and assess this module to determine its sustainability, academic coherence and viability. Arguably this module will be scrutinised for any limitations, and possibilities will be advanced for future consideration. Moreover students' assessment of the module is an integral and necessary step of the evaluation process. We propose that these responses will authenticate the need for its continued existence.

Williams, Patterson and Miller (2006) discuss the importance of research to refine practice, but indicate that there is a gap between research and family therapy practice. The authors address this critique by studying student reflections to guide best practice. Student evaluations may be systematically captured to best authenticate changed practices, but may not always be considered traditional research. There is a need to nurture a cyclical relationship between theory and practice, and analysing students' critiques is a healthy starting point. Moreover, adopting a student--centred approach and using their evaluations to shape curricula in higher education is now considered important, especially in assuring quality in the light of the University's Quality Promotions and Assurance Office. Wright (2000) agrees with this need for a student centred approach especially in service learning.

The Family Therapy Practice Module is located in the discipline of Social Work within the School of Social Work and Community Development, where the authors are employed. This postgraduate, part-time module has trans-disciplinary appeal, registering students who come not only from social work but also theology, nursing, medicine and education. The theory module, which is a prerequisite for the practice module, is taught in the first semester and covers the major theoretical models in family therapy, followed by the practice module (the subject of the analysis) in the second semester.

Students work with "live" families generally across a one-way mirror. All students are involved in every session either as principal therapist or as a member of the supervisory team serving the family. The Milan overview and format are used to structure the session, which traditionally uses a reflecting team behind a one-way mirror (Tomm, 1984). However, Milan Family Therapy may be supplemented or complemented with other schools of family therapy and other theoretical approaches learnt in the first semester, as family and therapist style dictate.

Students are assessed on their performance as team participants, as therapists and for demonstrating initiative in their learning such as complementing family therapy with appro- 
priate, specialist literature in relation to specific problems. Students benefit from several learning opportunities: team supervision, co-therapy which is used to build capacity (will be explained later) and individual supervision, all of which encourage critical reflection, to increase self-learning and promote service excellence. Written reports are also assessed in relation to the incorporation of family therapy theory, the creative inclusion of other relevant theories and accuracy in reporting the session.

\section{RESEARCH APPROACH}

The overall aim of the study was to appraise students' reflections of the Family Therapy Practice Module. This resulted in the achievement of several objectives as follows:

- Module review and adjustments;

- Preparation for discipline and institutional review of the module;

- Service delivery adjustments;

- Student empowerment as they realised how they could influence their own learning careers.

The research design was qualitative, specifically exploratory, using content analysis to interrogate the responses of all students taking the Family Therapy Practice Module in 2005. Although all questions were answered, there was some measure of disproportion in the responses, based on what students felt strongly about, e.g. supervision, circularity and neutrality yielded a great deal of comment. Often actual words of students are used so as not to influence meaning and to reflect the rich descriptions yielded in qualitative analysis (Babbie \& Mouton, 2001).

The students/respondents, four in number, female, Indian and from teaching, theology and social work, were between the ages of 30-57 and responded to a series of questions on their learning and growth during the year. To secure sufficient thought and attention to the exercise, it was linked to examination preparation at the conclusion of the semester. Despite the limited number of students, the authors believe that the rich, in-depth data adequately guided the shape and form of the module, this being in synchrony with qualitative research with in-depth investigation of a small sample. Furthermore, the distance between the role of researcher and that of trainer was small but this did not invalidate the findings, as it is this involvement that inspired seeing the world through the eyes of the respondents, gleaning rich data and "immersion" in the research process (Babbie \& Mouton, 1998:168).

The data analysis strategy relevant to this study was inductive reasoning, scrutinising data for establishing relationships or patterns. The Huberman and Miles Approach described in De Vos (1998) was found to suit the purposes of the study. This approach consisted of three linked processes of data reduction, data display and drawing conclusions.

This strategy allowed for recommendations to be made for future practice and module shaping.

\section{THEORETICAL UNDERPINNING}

According to Stratton $(2005: 219)$, it is wise to "construct new training in ways that maximize functional learning for each, different learner". Individualised learning using a postmodern perspective served as the philosophical and theoretical underpinning of both the module offering and the study.

To this end, multiple resources were deployed to maximise on the learning process to include reflective thinking, reflexive thinking and critical thinking. Fook (2002:43) comments that reflective thinking is particularly concerned with identifying the process of working things 
through, while reflexive thinking is concerned with the stance of taking into account many different perspectives. Critical thinking means not taking for granted the present social order, but actively looking for change. Our students were exposed to marginalised aspects of their experience such as emotions and personal history, the supervisor's influence in a session and how this might affect power relations (Allan, Pease \& Briskman, 2003).

From our experience, student diversity was represented by having a group of students from differing contexts, recognizing the power of their won words and quoting these in the article and facilitating students taking responsibility for their own knowledge acquisition.

Team supervision, individual supervision, co-therapy and the written report were all used. This allowed for learning areas to be openly experienced and discussed. Differential needs and learning paces were respected, notwithstanding this being a time-consuming venture. The authors are acutely aware that initially students need to build their confidence. Edwards and Patterson (2006) also state that students struggle with confidence: they feel daunted, intimidated and overwhelmed during this critical period of "imprinting". How we helped was by affirming our students' incremental growth spurts and the expertise they brought to the therapy encounter, again in accord with a postmodern perspective of valuing "the other". In addition, during this process of student learning there was a constant redefinition and reconstruction of the supervisors' (the authors') roles via post supervision evaluation meetings, this being consistent with the postmodern epistemology of learning as a reflexive process.

The supervisor-supervisee relationship needed to be embedded in postmodernism, using a theoretical frame that clearly devalued power relations despite these being generally acknowledged as being unequal in such relationships. In a study by Murphy and Wright (2005) it is suggested that power in the relationship be openly acknowledged. The most power-laden aspect emerges during evaluation and, since this is ongoing, it is ever-present. This means alerting the supervisee to when the supervisor exceeds the boundaries of confidentiality for the purpose of academic evaluation. In this review and indeed throughout the module offering, power relations are de-emphasised and evaluations are co-authored by both parties. What is different about such an evaluation process compared to the evaluation of undergraduate students' fieldwork, one may ask? In this postgraduate evaluation the student's maturity, the multiple supervision contexts and the on-site contact with students infuse integrity and openness into evaluative discussions, with reflexivity being the core driving principle. Pablo Freire (1990) aptly noted that students need to be recipients of information as subjects and not objects. The pedagogical method of self-reflection promotes and facilitates learning. Guanipa (2003:88) contends that if educators behave as equals in the learning process along with students, they share the responsibility in the training.

\section{RESULTS AND DISCUSSION}

Students were allowed one week to complete the task of answering a series of questions pertaining to the module and their training. Students' permission was sought to disseminate findings in respect of their responses. The data captured intellectual arguments, personal thoughts and feelings (Fook, 1999:195) and thereby offers a rich description of each area in question.

Each question was selected so as to evaluate key aspects in the module and contribute to module development. This was significant, because family therapy has often been regarded as benefiting people from first world countries, whereas through this module offering, its current structure and content have been remodelled to suit South African families. 


\section{THEME 1}

Using personal/professional experience, reports, supervisory evaluation sessions and team inputs, evaluate circularity, neutrality and hypothesizing as central theoretical constructs in Milan family therapy practice: (This was asked to yield data on the core components of the theory applied in the practice and to evaluate its relevance and usefulness.)

\subsection{Circularity}

This is the capacity of the therapist to move away from linear causality to multiple causality so that questions, being accordingly structured, may yield rich data pertaining to the complex interplay of forces and factors that determine behaviour and patterns in families. Tomm's (1984) series of circular questions were carefully applied by students in this regard. Students in general found that circular questioning yielded in-depth information not only to the therapist and team but also to families, saying: "...circularity provided facilitated intervention..." and “...it allows the family to witness its own transactional patterns".

It was also regarded as an "art" that required practice to get maximum mileage out of it. And one student said: "...circularity requires practice, adjustment and acclimatizing to a new language".

To this end, the authors note that the postmodern perspective of power reduction and comfort in learning encourages many students to continue attending practice sessions for their own ongoing learning!

Recognizing how valuable circularity is, the authors have accordingly been more deliberate in learning pertaining to this component. They now request that students identify each question category theoretically in the session's report, and expect students to critically reflect on its value or how circular questions could have been asked differently to yield optimum results. This is discussed during supervision.

\subsection{Neutrality}

Tomm (1984) indicates that the principle of neutrality refers to an attitude on the part of the therapist in relation to the family. It includes a sense of respect, acceptance, curiosity, fascination and even to some extent admiration of the system.

This pillar of Milan Family therapy concerns both attitude and behaviour that reflects neutrality, so that multiple voices of all within the system are accorded equal respect (Kasiram, 1998). Again, this premise of Milan Therapy has received wide support of late in keeping with respecting difference and culture specific ways of renewing that openly acknowledge and support variations (Kasiram \& Oliphant, 2005). Students found this theoretical aspect both challenging and exciting as indicated in the following responses:

"...began questioning whether neutrality is a myth...I felt strongly against a 23-year-old boy dating and later marrying a 45-year-old woman...!"; and “...aspects of neutrality were difficult... no one can be neutral all the time".

These responses show that students were prepared to practise neutrality, recognising its potential worth, but often found that its practice was a lot more difficult. The team is now alert to this difficulty and actively encourages interrogation of neutrality of all team members before each session, when we jointly hypothesise to plan for the session, during the mid-session break where the prescription is formulated, and at the end of the session when therapeutic effect is gauged. As teachers, we have questioned blind applicability of neutrality with South African families. When trauma and tragedy affect the people we work with and when similar levels of 
hurt are easily recognizable because of our own experience thereof, it is almost impossible and sometimes counter-productive not to take sides (Khoza, 2007). The question is: what degree of neutrality is required to guide responsible and relevant practice? The answer has not yet been ascertained, with issues of client respect, secondary trauma of the therapist, self-disclosure, curiosity and empathy vying at different times for top position.

\subsection{Hypothesising}

Tomm (1984:257), defines hypothesising as [need a verb here - "generating"?] "suppositions, hunches maps, or alternative explanations about the family and the 'problem' in its relational context". It allows one the freedom to explore a myriad of possibilities, whilst not being married to them, to manoeuvre in whatever direction the feedback takes one. This lends flexibility to therapy.

This component was novel to students and thoroughly enjoyed. As in research, where hypotheses are about possibilities that are advanced for testing, in family therapy, hypotheses allow the therapist to advance possibilities for exploring in session, to prepare for the session and lead the family from one step behind. Students said:

"I found hypothesising to be brilliant ... kept the interview focused";

"...it is heartening to see hypotheses from previous sessions come alive and being so accurate. I felt great, almost as if I had hidden powers".

Acknowledging these comments, the authors now structure session reports in accordance with the hypotheses explored as these revolve around themes and circular questions that link with each other. That helps achieve a systemic view of the family in a context that allows us to continue to give import to hypothesising.

\section{THEME 2}

\subsection{Evaluate costs and benefits of team supervision}

This question was asked because many students found that team supervision was a new experience and the authors wished to entrench what worked and discard aspects that may have been unhelpful. Team supervision was about securing a team mindset and best practice outcomes. It occurred before the session to hypothesise together after the therapists had individually prepared a series of hypotheses that they believed would be relevant; it occurred in the mid-session during the formulation of an overall hypothesis and prescription for the family, and post-session to gauge family receipt of the prescription, therapeutic effect and assess therapists. Edwards and Patterson (2006) and Singh (2005) also note that trainees look to supervisors and colleagues for instruction, reflection and modelling. Students mentioned the following regarding working with a team of professionals:

"they simultaneously supported and supervised; shared responsibility; team becomes the "watchdog"; each member learns from the strengths of the other; (allows) modelling and transference of positive skills and techniques; members have equal status - a safe environment for admitting areas of development; allows for a multi-disciplinary perspective; family feels assured that several persons with diverse experiences are helping them, getting the very best help; speaking with one team voice impacts as a dynamic message, e.g. in the prescription".

One student was most impressed by the prevailing, amiable team spirit nurtured by the authors (teachers), referring to it as the "backbone" behind the success of the therapy. A postmodern perspective is hereby employed, reversing traditional power differences and giving credence to 
students and family. Responses mark high levels of appreciation of team support, resulting in time, effort and space being found in each therapeutic encounter for team support.

The impact of multiple voices via the team supervision creates a stronger awareness of developmental areas and fast tracks change.

\subsection{The reflecting team within the room}

The authors use the reflecting team as explained above. However, how they use this has evolved over time with the current status being dictated by the number of families that attend the Clinic and the resources available for behind-the-scenes teamwork. In the recent past the authors have found that the use of a reflecting team within the room has appeal for the family in that it appears to eliminate power difference between family and therapeutic team. This benefit has been acknowledged by Andersen (2000). Fischel, Buchs, McSheffrey and Murphy (2001:83) report on the first reflecting team in 1985 by Andersen in Norway. Andersen indicated the usefulness to the family and the therapist that "we might talk while they listened to us". With the team speaking directly to the family, in an unrehearsed way, and in many voices, the idea of the reflecting team was born. Students were afforded the opportunity of using a one-way mirror (team behind) with an intercom and videotaping facilities or the reflecting team was placed within the same room as the family and principal therapist. The responses were mainly positive for the in-room reflection despite the one-way mirror affording videotaping and learning opportunities. Students said:

"...having the team in the same room was even better... the team (was) able to channel the discussion more openly... there is transparency; need to phrase themselves carefully as the family overhears; ... sometimes the family may find the team intrusive; sometimes the room is small resulting in discomfort and overcrowding...team members' chatter can be disruptive, goes against etiquette"; sitting behind the one-way mirror creates curiosity in the family".

It would appear that there were generally more favourable comments on team input within the room than when using the one-way mirror. However, unanticipated events occur both with family interaction and team dynamics, and may influence the choice for a barrier between family and team. Such events may be a young man declaring his felt abhorrence towards his father in the father's presence or where team members differ radically regarding therapist intervention/behaviour, resulting in the family witnessing many reactions and messages that would confound rather than help. Both variations of live supervision provide an avenue for "intense learning" that is immediate and produces results (Charles et al., 2005:219). The family dynamics, therapist comfort and available resources dictate the course of action.

Live supervision with team support offers supportive dialogue as the family observes, may externalise oppression and expand on success and resilience, creating a network of support for the isolated (Singh, 2005; Estrada, 2005). This is particularly relevant for South African families that have been marginalised and/or oppressed, and who cannot conceptualise themselves as worthy to experience a different life. Clearly an anti-oppressive stance guides the authors in their deliberate employment of reflection within the room!

Stratton (2005) suggests that family therapists (trainee students) spiral learn, meaning that they experience, reflect on that experience and generalise the specific experience to their own and other team members' experiences, thereby applying learning to novel situations, this culminating in new learning. From a postmodern perspective, the authors promote such spiral learning, creating discursive spaces for reflection within a team and an individual supervisory 
milieu that downplays power. Such a stance respects the expertise of students, especially when they come as adult learners who take responsibility for shaping their own learning. Ware and O'Donnoughue (2005) discuss reflective learning, where students use reflective comments to integrate their personal and professional development. Other authors who refer to the personalprofessional reciprocal relationship are Paris, Linville and Rosen (2006). These authors refer to aspects of personal growth that positively influence professionalism such as self-awareness; confidence; perspective talking; letting go; open-mindedness and building communication skills. Professional learning that influences personal growth included skill building; knowledge building and hopefulness. Many of these growth areas were cited by students during individual and team supervision.

\section{THEME 3}

\section{Critique the use of Co-therapy in sessions}

Edwards and Patterson (2006) note that all training sessions produce stress and anxiety. With this in mind, co-therapy was introduced to maximise students' learning, to ease students into the principal therapist role with support, and create spaces for students to interrogate their comfort and expertise in family therapy. Each student had an opportunity to begin the training as a co-therapist with an enabling role and then progressed to the role of main or principal therapist. Supervisors themselves modelled co-therapy, thereby illustrating the benefits of partnering at a dyadic level.

The following was reported by students on co-therapy:

“...did not know when the appropriate moment to join in was ... having a co-therapist from a different discipline complements”.

The easing in of therapists into the role of main therapist has been challenging. It was apparent that using co-therapy to support students into this role was more helpful than difficult. What has been learnt from students and incorporated into training is that co-therapy also means that, when weekly "individual supervision" takes place, time needs to be set aside for therapists to plan to work together. This has offset the criticism made in respect of not knowing when to intervene. In addition, the actual support offered by the co-therapist needs to be quantified in percentage terms so that dominant personalities do not infringe on a partner's development.

\section{THEME 4}

\section{Critique the use of prescription in sessions}

The prescription delivered at the end of Milan Family therapy is a message to the family by the team and therapist, to acknowledge strengths and to unbalance the family so that change and growth may ensue. The authors agree with Fischel et al. (2001) on the benefits of prescriptions providing a written record for future reflection, when families may "hear" reflections with which they may engage intellectually after their emotional turmoil has settled. Prescriptions document team comments, treatment plans with difficult or controversial reflections being attributable to the team; affirm the work the family still needs to do and to re-evaluate treatment. These are reflected in some of the student responses:

“...satisfying; ensured the team's message was shared with the family; allows for consolidating our thoughts as members of a team; repeating the prescription is uncomfortable as is not allowing discussion or acknowledgement from the family after it is read...I understand that they need time to absorb what the team observed and expressed, but surely they had a right to express whether or not they agreed with the team!" 
This latter comment has now produced change, in that prescriptions are not re-read, unless requested and comment is allowed from the family. This ensures that the final contact with the family is not abrupt, allows families to contribute to re-authoring their lives, and favours a postmodernist stance. The authors also appreciate the significance of the prescription and therefore deliver a written one to the family, this being handwritten by one of the team members in 'neat writing'.

\section{THEME 5}

\section{What helped/hindered therapeutic effect in working with families?}

Therapeutic effect is evaluated during team reflections and during individual supervisory sessions with trainees. It was deemed important to ascertain what promoted or hindered effectiveness. Students cited the following:

“...solid grounding in theory; additional reading pertaining to the problem specialty encouragement, expertise/passion and constant guidance of supervisors who were open to criticism; amiable team spirit with humour; having a co-therapist/team from different disciplines/backgrounds; use of spirituality; circular questions”.

The supervisee-supervisor relationship is traditionally an unequal one, yet this was not a felt experience of students. On the contrary, they afforded value to the relationship being nonhierarchical in the therapy room. In a study by Murphy and Wright (2005) it is suggested that power in the relationship be openly acknowledged. The most power-laden aspect arises during evaluation and since this is ongoing, it is ever present. This means alerting the supervisee to when the supervisor exceeds the boundaries of confidentiality for the purpose of academic evaluation. Students were appraised of the weekly supervisory meetings between supervisors and they fully appreciated that both supervisors had on-site knowledge of the other supervisor's students. This allowed students to believe that evaluation was fair and transparent. Further, students' own evaluations were formally recorded by them and assessed with them weekly during individual supervision. Another area where power interplay could negatively affect student learning and relationships amongst supervisors and amongst supervisees is favouritism, especially where several supervisors are used and where it is possible to present one's own student as the "best". This did not happen because of the on-site "preview" of each other's students, a practice that is time consuming but essential in aggressively pursuing minimum interference that mat result from power differences.

Faber and Heiftez (in Paris et al., 2006:47) note that therapeutic work increases, and growth and learning are optimised, when team learning is used. This was evident from responses on the camaraderie enjoyed amongst supervisees while they together learnt from and through the team relationship.

The supervisor's humility, passion and openness clearly contributed to module success. The supervisors moved beyond their own comfort zones by challenging traditional supervisory styles, were open to self- and student criticism, and instilled critical consciousness in shaping the landscape of teaching and learning of family therapy. This postmodern perspective benefited both the student and supervisor.

\section{THEME 6}

\section{Evaluation of the module and recommendations (general)}

To invite all possible contributions to module evaluation, this general question was asked. Responses that covered new areas were: 
"...family therapy should be taken into the community; employ a co-ordinator to keep the family clinic running; when video taping, if families are uncomfortable, maybe audio taping should be explored; market family therapy".

These responses have already borne fruit with a community family therapy model being researched and implemented in a local, urban and impoverished community. This is new ground that has only recently been acknowledged as a developmental area in family therapy as we increasingly encounter infrastructural disadvantage in families and communities (Engelbrecht \& Kasiram, 2006. Dominelli (2005) and Ife and Fiske (2006) advise - and the authors agree - that success and sustainability in work with communities requires "commitment to working in egalitarian value systems, as well as holistic approaches to social, economic, physical and spiritual environments in which people carve out their daily lives". Community family therapy needs to be sensitive to context, employ a non-judgemental approach, engage all stakeholders and multiple systems, and respect daily hardships and realities that challenge the adoption of neutrality. The authors have now included seminars on community family therapy into the prerequisite module family therapy theory module to facilitate dialogue and debate in this area.

The service has not been taken out of the University setting into the community, nor has a coordinator been employed because of financial restraints (travel costs and salary).

The dialogical engagement between supervisor/trainer and student was clearly valued. Faber (2003:7) agrees that such a dialogical process speaks to the said, the unsaid, and the yet-to-be said, this being manifested in the module offering through open-hearted sharing and communication.

\section{CONCLUSIONS}

This study has provided qualitative information to support the view that student reflection is integral to curriculum design. Student reflection was experienced as a substantial reality in shaping the module, and kept the authors humble yet vigilant to maximise learning outcomes. The module was concerned with sharing of wisdom, the collecting of others' expertise, while also intervening and building relationships that furthered the goals of good clinical practice from a postmodern perspective. It also incorporated diversity, power negotiation and role fluidity, these attributes being discussed by authors of family therapy such as Ungar (2006).

With the module being thus "audited" by students who have been empowered to shape its content, the authors believe that it can now stand up to the scrutiny of the larger university community for appraisal.

\section{RECOMMENDATIONS}

Recommendations regarding module adjustments have been discussed under each section as per question order. A literature search yielded some novel ideas that may be worth considering in future module adjustment and change. These include the following:

- Walker (2005) discusses the value of poster presentations in evaluating student work. He discusses the pride taken in putting together work undertaken in the module. The poster allows students to showcase their work using creative energy; encourages teamwork and self-evaluation; and reduces the prospect of plagiarism and general copying. Our students could use the poster as a medium for evaluating the module and their learning. A further consideration is that these posters could be utilised during in-service at the organisations 
that students are employed, to market the module, heeding one of the recommendations made by the students.

- Cultural competence, racial inclusivity and social justice training may also be regarded as very important to enable students to work effectively across racial and cultural divides. It is not enough simply to have team members of different cultures/races informing and guiding practice. Deliberate engagement with the range of problems manifested through experience of diversity and injustice need attention (Inman, Meza, Brown \& Hargrove, 2004; Guanipa 2003). Students' cultural contexts, their prejudices, biases and ethnicity added to a myriad of emotions and thoughts about contentious decisions taken within the therapeutic interventions. The value of cultural and contextual considerations in family work cannot be ignored. As educators we need to be culturally reflective, and could begin this process with a cultural genogram of our own lives and experiences. Guanipa (2003:96) also recommends it as a strategy to develop awareness of one's cultural self. Students could be encouraged to keep a journal to maximise their own learning and this will invariably create space for introspection, interrogation of thought, and critique of their own actions, and discussed during individual supervision. This will ensure that students take responsibility of their own learning.

- A further feature amongst families in South Africa and abroad is the bi-racial or multiracial family (McDowell et al., 2005). These families encounter "disfavour and outright prejudice quite regularly", say Milan and Keiley (cited in McDowell et al., 2005:401). It is here that the collective might of team support may be clearly apparent, when many voices together express concern for injustices experienced and give permission for change and growth. Once again students could engage in purposefully interrogating their own prejudices and stereotypical views on race and race relations and the issues of power that prevail in society via personal genograms.

- Eisler (2003:3) aptly notes the perception of reluctance or only a grudging acceptance of the value of practice research, which is unhelpful for the development and advancement of family therapy or social work in general. We should challenge this perception by actively disseminating practice research findings and asking that space be created in local and international journals for their inclusion.

\section{REFERENCES}

ALLAN, J., PEASE, B. \& BRISKMAN, L. 2003. Critical social work: An introduction to theories and practices. Australia: Allen \& Unwin.

ANDERSEN, T. 2000. Opening address: Reconciliation, is it always possible? X11 IFTA Family Therapy World Congress, Oslo, Norway.

BABBIE, E. \& MOUTON, J. 1998. The practice of social research. New York: Oxford University Press.

BABBIE, E. \& MOUTON, J. 2001. The practice of social research. Cape Town: Oxford University Press.

CHARLES, L.L., TICHELI-KALLIKAS, M., TYNER, K. \& BARBER-STEPHENS, B. 2005. Crisis management during "live" supervision: Clinical and instructional matters. Journal of Marital and Family Therapy, 31(3):207-219.

DE VOS, A.S. 1998. Research at grassroots. Pretoria: J.L. van Schaik. 
DOMINELLI, L. 2005. Community development across boarders: avoiding dangerous practices in a globalizing world. International Social Work, 48(6):702-713.

EDWARDS, T.M. \& PATTERSON, J.E. 2006. Supervising family therapy trainees in primary care medical settings: Context matters. Journal of Marital and Family Therapy, 32(1):33-43.

EISLER, I. 2003. Strengthening the links between research and practice. Journal of Family Therapy, 25(1):3.

ENGELBRECHT, C. \& KASIRAM M. 2006. Assessing and serving families and communities responsibility: Challenges posed in an urban marginalised setting. Paper presentation at XV IFTA conference, Iceland.

ESTRADA, D. 2005. Supervision of cross-cultural couple therapy: Giving a voice to the Code of Silence in the supervision and therapy room. Journal of Family Psychotherapy, 16(4):1730 .

FABER, A.J. 2003. Therapy with the elderly: A collaborative approach. Journal of Family Psychotherapy, 14(4):1-14.

FISCHEL, A.K., BUCHS, T., McSHEFFREY, C. \& MURPHY, C. 2001. Adding written reflections to the reflecting team. Journal of Family Psychotherapy, 12(3):81-88.

FOOK, J. 1999. Critical reflectivity in education and practice. In: PEASE, B. \& FOOK, J. (eds) Transforming social work practice: Postmodern critical perspectives. London: Routledge.

FOOK, J. 2002. Social work: Critical theory and practice. London: Sage.

FREIRE, P. 1990. Pedagogy of the oppressed (transl. by M.B. Ramos). New York: Continuum.

GUANIPA, C. 2003. Sharing a multicultural course design for a marriage and family therapy programme: one perspective. Journal of Family Therapy, 25(1):86-106.

IFE, J. \& FISKE, L. 2006. Human rights and community work. International Social Work, 49(3):293-308.

INMAN, A.G., MEZA, M.M., BROWN, A.L. \& HARGROVE, B.K. 2004. Student-faculty perceptions of multicultural training in accredited marriage and family therapy programs in relation to students' self reported competence. Journal of Marital and Family Therapy, 30(3):373-388.

JONES, M. \& JORDAN, B. 1996. Knowledge and practice in social work. In: PRESTONSHOOT, M. (ed) Social work education in a changing policy context. London: Whiting \& Birch.

KASIRAM, M. \& OLIPHANT, E. 2005. Challenges and changes to family therapy practice in South Africa. AFTA Monograph Series. Lessons Learned in Community Practice, 1(2):3339.

KASIRAM, M. 1998. Neutrality in the face of trauma. Maatskaplike Werk/Social Work, 34(3):307-310.

KHOZA, V. 2007. Responses on non-governmental organisations to the needs and expectations of volunteer trauma support workers within the victim empowerment sector 
in KwaZulu-Natal. Durban: University of KwaZulu-Natal. (Unpublished Masters Dissertation)

MCDOWELL, T., INGOGLIA, L., SERZAWA, T, HOLLAND, C. \& DASHIELL, J. W. 2005. Multiracial awareness in family therapy through critical conversations. Journal of Marital and Family Therapy. 31(4): 339-411.

MURPHY, M.J. \& WRIGHT, D.W. 2005. Supervisees' perspectives of power use in supervision. Journal of Marital and Family Therapy, 31(3):283-296.

PARIS E., LINVILLE, D. \& ROSEN, K. 2006. Marriage and family therapist interns' experiences of growth. Journal of Marital and Family Therapy, 32(10):45-58.

PAYNE, M. 2005. Modern social work theory ( $3^{\text {rd }}$ ed). New York: Palgrave.

SINGH, R. 2005. Therapeutic skills for working with refugee families: an introductory course at the Institute of Family Therapy. Journal of Family Therapy, 27(3):289-292.

STRATTON, P. 2005. A model to coordinate understanding of active autonomous learning. Journal of Family Therapy, 27(3):217-236.

TOMM, K. 1984. One perspective on the Milan Systemic Approach: Part 11. Description of session format, interviewing style and interventions. Journal of Marital and Family Therapy, 10(3):253-271.

UNGAR, M. 2006. Practicing as a postmodern supervisor. Journal of Marital and Family Therapy, 32(1):59-72.

WALKER, S. 2005. Poster on the wall: whose is the fairest assessment of all? Journal of Family Therapy, 27(3):285-288.

WARE, G. \& O'DONNOUGHUE, E. 2005. Student learning styles and assessment on a family therapy training course. Journal of Family Therapy, 27(3):293-297.

WILLIAMS, L.M., PATTERSON, J. E. \& MILLER, R. 2006. Panning for gold: A clinician's guide to using research. Journal of Marital and Family Therapy, 32(1):17-32.

WRIGHT, R.E. 2000. Quality factors in Higher Education: The students viewpoint. College Student Journal, 30:269-272.

Ms Rubeena Partab (MMed Science, Social Work) and Dr Madhu Kasiram are lecturers in the School of Social Work and Community Development, University of KwaZulu-Natal, South Africa. 